\title{
Tatakrama Kepemimpinan Sunda dalam Novel Sejarah Tanjeur na Juritan Jaya di Buana
}

\author{
Retty Isnendes, Ruhaliah, Dedi Koswara, Ruswendi Permana \\ Universitas Pendidikan Indonesia \\ retty.isnendes@upi.edu
}

\begin{abstract}
Sejarah Artikel: Diterima (18 Januari 2019); Diperbaiki (15 Maret 2019); Disetujui (30 Maret 2019); Pusblished (30 April 2019).

Bagaimana mengutip artikel ini (dalam gaya APA): Isnendes, R., Ruhaliah, Dedi, K., dan Ruswendi P. (2019). Tatakrama kepemimpinan Sunda dalam novel sejarah Tanjeur na Juritan Jaya di Buana. Lokabasa, 10(1), 1-11. doi: 10.17509/jlb.v10i1.16943
\end{abstract}

\begin{abstract}
Abstrak: Ada anggapan bahwa kepemimpinan Sunda lemah sehingga tidak dapat bersaing di panggung nasional. Padahal sejarah mencatat sejumlah nama pemimpin panutan Sunda, misalnya saja Prabu Wangi, Prabu Niskala Wastu kancana, dan Sri Baduga Maharaja. Dalam tataran sastra nama Prabu Siliwangi merupakan ikonitas dan simbolitas pemimpin Sunda yang besar dan berhasil sepanjang masa. Ikonitas dan simbolitas pemimpin Sunda tergambar juga dalam novel sejarah Tanjeur na Juritan Jaya di Buana yang ditulis oleh Yoseph Iskandar. Unik dan utamanya, novel tersebut bersandar pada naskah Pangeran Wangsakerta dari Cirebon yang tahun 1980-an menggemparkan jagat kesejarahan Indonesia. Novel tersebut telah mendapat hadiah Rancage dari Yayasan Rancage Ajip Rosidi. Dengan menggunakan metode deskriptif dan teknik telaah pustaka dan interprerasi, novel tersebut akan dikaji tatakrama kepemimpinannya dalam lingkup etnopedagogik. Tujuan penelitian ini adalah untuk: (a) mendeskripsikan tatakrama kepemimpinan Sunda dalam novel, (b) mendeskripsikan aspek etnopedagogik dalam novel, dan (c) membandingkan tatakrama kepemimpinan masa lalu dan masa sekarang sebagai model pendidikan budaya. Hasil yang diharapkan adalah terdeskripsikannya tokohtokoh dalam kepemimpinan Sunda, tatakrama kepemimpinan Sunda, dan model pendidikan budaya dari novel yang dianalisis.
\end{abstract}

Kata Kunci: Kepemimpinan; novel Sunda, etnopedagogi

Sundanese Leadership Manners in Historical Novel Tanjeur Na Juritan Jaya Di Buana Works Of Yoseph Iskandar

Abstract: There is a presumption that Sundanese people leadership is weak and feeble so they can not compete on the national level. Though history recorded some names of Sundanese leaders, such as Prabu Wangi, Prabu Niskala Wastu Kanca, and Sri Baduga Maharaja. In the literature, the name of King Siliwangi is an icon and symbol of the great and successful Sundanese leader of all time. The identity and symbolism of the Sundanese leader are also reflected in the historical novel of Tanjeur na Juritan Jaya di Buana written by Yoseph Iskandar. Uniquely, the novel relies on the manuscript of Prince Wangsakerta from Cirebon which in the 1980s appalled Indonesia history. The novel has been awarded Rancage from Ajip Rosidi's Rancage Foundation. By using descriptive method and literature review technique and interpretation, the novel will be examined his leadership ethics in ethno pedagogic scope. The aims of this study are: (a) to describe the principles of Sundanese leadership in the novel, (b) to describe the etnopedagogical aspect in the novel, and (c) to compare the leadership principles of the past and the present as models of cultural education. The expected outcomes are the descriptions of figures of Sundanese leadership, Sundanese leadership manners, and the cultural education model found in the novel analyzed.

Keywords: Leadership; Sundanese novel; ethno-pedagogic 


\section{PENDAHULUAN}

Meskipun Jakarta ada di Jawa Barat, akan tetapi tidak menjamin orang Sunda menjadi pemimpin dan berkiprah di panggung politik dan pemerintahan. Semenjak negeri ini menjadi Republik, dari sekian Presiden sebagai pemimpin nomor satu belum ada yang dari etnik Sunda. Etnik ini dalam kepemimpinan bangsa, kuantitasnya baru ada yang menjadi RI-2, yaitu Bapak Jendral (Purn) Umar Wirahadikusumah.

Selanjutnya, turun pada kepemimpinan dalam taraf mentri, pun kurang eksis. Pada kabinet sekarang saja (2014-2018), mentri yang berasal dari etnik Sunda bisa dihitung dengan tiga jari. Belum lagi anggota DPRD/DPR-RI bila diamati, sangat sedikit etnik Sunda yang menjadi wakil rakyat, bahkan di Provinsi Jawa Barat, persentase wakil rakyat dari etnik ini lebih sedikit dari etnik yang lainnya.

Hal tersebut dikuatkan oleh politikus perempuan yang disebut Singa Betina, Ibu Dr (H.C) Hj. Popong Otje Djundjunan yang dalam setiap kesempatan dan obrolan, selalu mengajak generasi muda untuk ikut terlibat dalam politik dan jangan menjauhi politik jika orang Sunda ingin berkiprah secara nasional. Tokoh Sunda pun, Drs H. $\mathrm{Uu}$ Rukmana yang merupakan mantan wakil ketua DPRD Jabar, mendorong masyarakat Sunda untuk mengambil peran dalam kancah perpolitikan Nasional. Menurut beliau, di era reformasi ini, orang Sunda belum ada yang mengambil peran sebagai pimpinan Nasional (http://jabarprov.go.id).

Walaupun demikian, di semua level kepemimpinan, orang Sunda pernah merasakannya. Sebut saja, untuk jabatan menteri, Kapolri, Panglima ABRI atau kini TNI, bahkan salah satu putra terbaik Sunda pernah menjabat perdana menteri, yakni Djoeanda Kartawidjaja. Di legislatif pun, kendati tidak berada di puncak, setidaknya orang Sunda pernah memimpin, melalui Ginandjar Kartasasmita yang menjabat
Ketua Dewan Perwakilan Daerah (http://m.inilah.com).

Apakah yang menyebabkan demikian? Padahal sejarah mencatat sejumlah nama pemimpin panutan Sunda, misalnya saja Prabu Wangi, Niskala Wastu Kancana, dan Sri Baduga Maharaja. Dalam tataran sastra nama Prabu Siliwangi merupakan ikonitas dan simbolitas pemimpin Sunda yang besar dan berhasil sepanjang masa. Akan tetapi keberhasilan sebagai pemimpin (raja Sunda) tidak diwariskan secara politis, genetik, dan historik pada orang Sunda setelahnya.

Ikonitas dan simbolitas pemimpin Sunda yang hebat dan agung tergambar juga dalam novel sejarah Tanjeur na Juritan Jaya di Buana yang ditulis oleh Yoseph Iskandar. Unik dan utamanya, novel tersebut bersandar pada naskah Pangeran Wangsakerta dari Cirebon yang tahun 1980-an menggemparkan jagat kesejarahan Indonesia. Pangeran Wangsakerta adalah tokoh luar biasa yang mampu mengumpulkan tokoh-tokoh sejarah pada jamannya untuk menulis ulang dan merekontruksi peristiwa sejarah Nusantara secara lengkap dan sempurna.

Usaha mengenalkan apa yang sudah dikerjakan oleh Pangeran Wangsakerta, telah dilakukan oleh Prof. Dr. Ajatrohaedi semenjak tahun 1981, Yoseph Iskandar tahun 1983, dan saleh Danasasmita 1982 (https://artshangkala.wordpress.com).

Yoseph Iskandar seorang sastrawan Sunda, selain menulis buku tentang Sejarah Jawa Barat yang bersandar pada naskah Pangeran Wangsakerta tersebut, juga mereinterpretasi peristiwa-peristiwa sejarah Sunda melalui karya sastranya dalam bentuk roman sejarah atau novel sejarah.

Karya-karya beliau yang monumental dalam bentuk novel adalah: Perang Bubat (1988), Wastu Kancana (1989), Prabu Wangisutah (1991), Tanjeur na Juritan, Jaya di Buana (1991), Pamanahrasa (1991), Putri Subanglarang 
(1991), Prabu Anom Jayadéwata (1996), Tri Tangtu di Bumi (1996). Novél Tanjeur na Juritan Jaya di Buana mendapat Hadiah Sastra Rancagé (1992). Selain itu, novél sejarah lainnya Tri Tangtu di Bumi juga mendapat Hadiah Sastra Rancagé 1997 dari Yayasan Rancage Ajip Rosidi (https://su.wikipedia.org).

Novel yang akan dikaji karya Yoseph Iskandar ini mempunyai materi mengenai kepemimpinan dan aturan dalam kepemimpinan. Kepemimpinan dalam zaman Kerajaan Sunda yang sangat menarik bila menjadi model etnopedagogik di masa kini. Selain itu, tak menutup kemungkinan, lemahnya kepemimpinan Sunda masa kini karena tidak mencontoh dan meneladani pemimpin Sunda yang diagung-agungkannya, di samping faktor lain yang mempengaruhinya.

Penelitian ini bertujuan mendeskripsikan tatakrama kepemimpinan Sunda dan etnopedagogik yang terdapat dalam novel Tanjeur na Juritan Jaya di Buana. Selain itu dideskripsikan perbandingan tatakrama kepemimpinan masa lalu dan masa sekarang sebagai model pendidikan budaya.

Novel Sunda. Ajip Rosidi (Isnendes, 2017:31) menyebutkan bahwa pada tahun 1914 sebuah novel Sunda lahir. Novel Sunda pertama tersebut berjudul Baruang Ka Nu Ngarora karya D.K. Ardiwinata atau Daeng Kanduruan Ardiwinata Tahun terbit novel Sunda ini dijadikan titimangsa bahwa sastra Sunda modern telah lahir di Tatar Sunda. Umur kelahiran novel ini lebih tua enam tahun dari pada novel sastra Indonesia Azab dan Sengsara Seorang Anak Gadis.

Perkembangan sastra Sunda modern, terutama novel, tidak lepas dari peranan Balai Pustaka. Penerbit ini adalah penerbit resmi pemerintahan kolonial yang dengan rutin mencetak dan menerbitkan novelnovel Sunda. Akan tetapi, usaha masyarakat Sunda sendiri yang dengan keras dan giat menerbitkan novel dan bukubuku Sunda perlu digarisbawahi. Penerbit swasta yang pada tahun 1930 telah menerbitkan sejumlah novel Sunda diantaranya adalah Dahlan Bekti dan Kusradie. Novel-novel yang diterbitkannya diantaranya adalah: Carios Agan Permas 'Cerita Agan Permas', Mugiri, Neng Yaya, dan Rusiah $\mathrm{Nu}$ Goreng Patut 'Rahasia Seorang Buruk Rupa'. Penerbit yang produktif menerbitkan novel dan genre lainnya setelah PD II adalah CV Rahmat Cijulang, CV Geger Sunten, dan Girimukti Pasaka, di samping penerbit-penerbit kecil di setiap kota yang ada di Jawa Barat.

Novel-novel Sunda yang terbit sebelum PD II dikarang oleh para penulis novel Sunda angkatan 1920-1940. Penulispenulis yang tercatat tersebut di antaranya adalah: DK Ardiwinata, Rd. Memed Sastrahadiprawira, Mohamad Ambri, Margasulaksana, Sambas, dan Susangka. Para penulis tersebut biasanya berprofesi sebagai guru atau seorang pendidik. Dengan demikian, karya sastranya pun tidak lepas dari karakteristik pendidik; memberikan pendidikan lewat karya sastra yang ditulisnya. Karya sastra yang dihasilkan oleh mereka menyebar luas di masyarakat, memberikan tuntunan, dan dijadikan acuan moral. Terlebih lagi, lahir penulis-penulis generasi muda kemudian lulusan Jurusan Pendidikan Bahasa Daerah (Sunda) IKIP Bandung, sehingga Duduh Durahman (1991:81) menyebut sastra Sunda sebagai sastra guru; sebagai konsekuensi profesi dan untuk sebagian isi karya yang 'mengajari'.

Setelah koran dan majalah terbit di Tatar Sunda, maka banyak penulis Sunda menulis dalam koran dan majalah tersebut. Novel-novel yang ditulisnya dimuat sebagai cerita bersambung. Para penulis yang karyanya sering dimuat dalam cerita bersambung di antaranya: Ki Umbara, Yus Rusamsi, Aam Amilia, Min Resmana, Caraka, Abdullah Mustappa, Ahmad Bakri, Adang S, Tatang Sumarsono, Holisoh ME, dan Pipiet Senja. Sampai tahun 20017 ini, telah ratusan novel diproduksi (Isnendes, 2017: 33). 
Novel Tanjeur na Juritan Jaya di Buana telah mendapat hadiah sastra Rancage dari Yayasan Rancage yang dipimpin oleh Ajip Rosidi. Lihat tabel pada halaman selanjutnya.

Tabel

Daftar Novel yang Mendapat Hadiah Sastra Rancage

\begin{tabular}{|c|c|c|c|c|}
\hline No & Karya & & Jasa & Tahun \\
\hline & Judul Novel & Penulis & Individu/Lembaga & \\
\hline 1. & Nu Kaul Lagu Kaleon (Novel) & RAF & Ki Umbara & 1991 \\
\hline 2. & $\begin{array}{l}\text { Tanjeur na Juritan Jaya di Buana } \\
\text { (Novel) }\end{array}$ & Yoseph Iskandar & M. Rustandi Kartakusuma & 1992 \\
\hline 3. & Demung Janggala (Novel) & Tatang Sumarsono & Sayudi & 1994 \\
\hline 4. & $\begin{array}{l}\text { Prabu Jaya Dewata dan Tri Tangtu } \\
\text { Di Bumi (Novel Sejarah) }\end{array}$ & Yoseph Iskandar & Wahyu Wibisana & 1997 \\
\hline 5. & Awewe Dulang Tinande (Novel) & Tjaraka & $\begin{array}{l}\text { RAF (Rahmatullah Ading } \\
\text { Affandie) }\end{array}$ & 1998 \\
\hline 6. & Galuring Gending (Novel) & Tatang Sumarsono & Edi Ekadjati & 2002 \\
\hline 7. & $\begin{array}{l}\text { Kembang-kembang Petingan } \\
\text { (Novel) }\end{array}$ & Holisoh ME & Tini Kartini & 2003 \\
\hline 8. & Panganten (Novel) & Deden A. Aziz & $\begin{array}{l}\text { Lembaga Kesenian } \\
\text { Yayasan "Cangkurileung" }\end{array}$ & 2004 \\
\hline 9. & $\begin{array}{l}\text { Amanat dina Napas Panungtung } \\
\text { (Novel) }\end{array}$ & $\begin{array}{l}\text { MH. Rustandi } \\
\text { Kartakusuma }\end{array}$ & K.H. Ahmad Maki & 2005 \\
\hline 10. & Sandekala (Novel) & Godi Suwarna & $\begin{array}{l}\text { Teater Sunda Kiwari (R. } \\
\text { Dadi Danusubrata) }\end{array}$ & 2008 \\
\hline
\end{tabular}

Yoseph Iskandar adalah pengarang Sunda yang produktif, dan karya-karyanya banyak mendapat hadiah sastra. Yoseph Iskandar lahir di Purwakarta 11 Januari 1953, beliau meninggal di Kecamatan Ujungberung, Bandung, 26 Maret 2008. Beliau adalah penyair, sutradara, penulis cerpen, novel, roman, dan drama dalam bahasa Sunda. Tamat dari SMA, Yoseph bekerja dan minatnya pada sastra sedemikian besar sehingga tercatat kemudian, bahwa beliau dengan rekan seangkatannya Eddy D. Iskandar, Godi Suwarna, Juniarso Ridwan, Beni Setia, dll membentuk organisasi untuk para sastrawan Sunda yang dinamai Durma Kangka (https://su.wikipedia.org ).

Beliau juga tertarik pada sejarah dan belajar sejarah pada ahli sejarah Saleh Danasasmita, terutama mempelajari naskah wangsakerta. Hal itulah kemudian yang memotivasi beliau menulis novel-novel sejarah yang ditukil dari naskah tersebut. Adapun novel-novel sejarahnya adalah demikian: Perang Bubat (1988), Wastu
Kancana (1989), Prabu Wangisutah (1991), Tanjeur na Juritan, Jaya di Buana (1991), Pamanahrasa (1991), Putri Subanglarang (1991), Prabu Anom Jayadéwata (1996), Tri Tangtu di Bumi (1996).

Tatakrama Kepemimpinan

Sunda. Kepemimpinan Sunda sebelum abad ke-16 telah diabadikan pada naskah Sanghyang Siksa Kandang Karesian yang selesai ditulis pada tahun 1518 M. Pada naskah tersebut ada yang disebut Parigeuing, Dasa Pasanta, Pangimbuhning Twah, dan Empat Larangan bagi pemimpin dan kepemimpinan (Danasasmita, 1987). Menurut Suryalaga (1994: 178), manusia Sunda sekarang harus bersyukur karena mempunyai naskah Sanghyang Siksa Kandang Karesian. Karena dengan naskah tersebut, manusia Sunda sekarang mempunyai bukti mengenai ilmu kesiliwangian, sehingga mengerti mengapa kepemimpinan raja Sunda, terutama yang 
digelari Siliwangi terus dianut dibanggakan dan digandrungi.

Kemahiran kemimpinan beliau (leadership) sangat hebat dan luar biasa sehingga dalam tatanan manajerial birokrasi tradisonal waktu itu 'raja-rakyat; sangat berhasil. Bahkan dikenang sampai sekarang. Hal tersebut tak akan mungkin terjadi jikalau kualitas sumber daya manusia atau kepribadian dan juga karakter beliau tidak unggul. Dengan diyakini dan dikenangnya juga dirindukannya Prabu Siliwangi oleh manusia Sunda, ini artinya kepribadian dan karakter beliau sungguh terpuji. Dalam bahasa agamanya adalah ahlak beliau sangat terpuji.

Etnopedagogik. Alwasilah dkk (2009 hal. 14) mengemukakan bahwa etnopedagogik adalah praktek pendidikan berbasis kearifan lokal dalam berbagai ranah seperti pengobatan, seni bela diri, lingkungan hidup, pertanian, ekonomi, pemerintahan, sistem penanggalan, dan lain - lain. Etnopedagodik memandang pengetahuan atau kearifan lokal sebagai sumber inovasi dan keterampilan yang dapat diberdayakan demi kesejahteraan masyarakat.

Kearifan lokal adalah koleksi fakta, konsep kepercayaan, dan persepsi masyarakat ihwal dunia sekitar, cara menyelesaikan masalah, dan memvalidasi informasi. Jadi, kearifan lokal adalah bagaimana pengetahuan dihasilkan, disimpan, diterapkan, dikelola, dan diwariskan. Etnopedagogik menekankan pada pentingnya pendidikan dihubungkan dengan kebudayaan sehingga proses dan hasil pendidikan membantu perkembangan peserta didik menjadi pribadi dewasa yang dapat bertanggungjawab secara sosial, budaya, dan moral, sesuai dengan norma yang ada di masyarakatnya.

Etnopedagogik merupakan pendidikan yang didasarkan pada etnografis, karena berkaitan erat dengan etnis. Pedagogik berkaitan dengan edukasi (education), educare (membimbing, mengajar). Jadi etnopedagogik merupakan ilmu pendidikan yang didasarkan pada etnis, budaya, dan adat-istiadat masyarakatnya, supaya peserta didiknya menjadi manusia yang unggul tetapi tetap berpijak pada budayanya. Sebagaimana yang dikemukakan oleh Alwasilah dkk. (2009 hal. 12), bahwa "Proses pendidikan yang bersandar secara kukuh kepada budaya amat penting guna melahirkan pandangan dunia, nilai-nilai, dan komitmen terhadap nilai-nilai dan keluhuran martabat manusia yang bertumpu pada kejujuran dan pertanggungjawaban". Pendidikan bukan hanya menyampaikan nilai teknis dan estetikanya melainkan juga pada aspek sosial budayanya.

Walaupun di Indonesia termasuk ke dalam teori baru, pelaksanaan etnopedagogik sudah lama dilaksanakan di Indonesia. Berbagai tradisi yang berkaitan dengan siklus kehidupan, ungkapan, pantun, dan lain-lain, merupakan bagian dari etnopedagogik yang berlangsung terusmenerus. Pendidikan tidak hanya berorientasi pada kurikulum nasional tetapi juga bagaimana mengembangkan potensi lokal yang dimiliki masyarakat, sehingga disediakan kurikulum muatan lokal. Hal ini dilakukan agar generasi berikutnya tidak kehilangan jati dirinya. Jadi di dalam etnopedagogik berusaha digali berbagai potensi yang dimiliki oleh suatu etnis, berbagai kearifan lokal, serta berbagai budaya bangsa yang terkandung di dalamnya.

Faktor-faktor yang menjadi pendukung dalam pendidikan terdiri dari peserta didik, pendidik, lingkungan dan sarana pendidikan, orang tua/wali siswa (Alwasilah dkk., 2009, hal. 34-42). Kelima faktor tersebut saling menunjang satu sama lain, walaupun tidak selamanya maksimal. Sumber-sumber etnopedagogik dapat ditemukan dalam tradisi lisan dan tradisi tulis, khususnya dalam novel.

\section{METODE}

Penelitian ini dilakukan dengan menggunakan metode kualitatif-deskriptif. 
Berbagai unsur yang berkaitan dideskripsikan dengan seteliti mungkin agar didapat kesimpulan yang representatif. Untuk mendeskripsikan data yang diperlukan digunakan teknik pengumpulan data berupa studi pustaka, sedangkan dalam pengolahannya digunakan teknik analisis, interpretasi, dan perbandingan.

Sumber data penelitian ini adalah novel Tanjeur na Juritan Jaya di Buana karya Yoseph Iskandar. Novel ini diterbitkan tahun 1991 oleh Yayasan Pembangunan Jawa Barat Jakarta. Naskah sebelumnya dierjakan oleh Yayasan Pembangunan Jawa Barat dan Penerbit Rahmat Cijulang Bandung.

Novel ini menceritakan kehidupan Prabu Wastu Kancana atau Prabu Wangisutah. Beliau merupakan anak raja Prabu Wangi yang gugur di Palagan Bubat. Diceritakan bagaimana beliau diangkat menjadi raja, menikah, mempunyai anak, dan memerintah dengan adil dan bijaksana. Keadilan dan kebijaksanaan beliau serupa dengan ayahnya Prabu Wangi. Dalam sejarah, masa tahta beliau adalah masa yang terlama yaitu 103 tahun 6 bulan 15 hari. Hal itu menunjukkan bagaimana tatakrama kepemimpinan dijalankan dengan baik oleh beliau, sehingga dicintai rakyatnya dan melanggengkan kepemimpinannya.

\section{HASIL DAN PEMBAHASAN}

Pada novel ditemukan aspek-aspek tatakrama kepemimpinan Sunda, terutama parigeuing, dasa pasanta, dan pangimbuhning twah pada tokoh utama novel Tanjeur na Juritan Jaya di Pangeran Niskala Wastu Kancana atau Prabu Wangisutah. Adapun opat larangan atau empat hal yang dilarang tidak terdapat pada tokoh utama, kecuali pada tokoh tambahan. Praktik pendidikan yang berdasarkan pada budaya Sunda dalam novel ini ada beberapa jenis, yaitu sebagai berikut: 1) suksesi kepemimpinan dalam pemerintahan kerajaan, 2) pendidikan kepemimpinan, 3) pendidikan agama dan budi pekerti, 4) strategi mempertahankan pemerintahan kerajaan. Tatakrama bersinonim dengan sopan-santun dan etika, yang dasarnya adalah karakter; watak; akhlak. Dengan demikian tatakrama kepemimpinan Sunda bersumber pada karakter atau watak yang baik yang dipunyai oleh pribadi pemimpin tersebut. Pada tataran tingkah laku (tatakrama), karakter itu tergambar pada nilai-nilai yang dianggap baik oleh orang Sunda tradisional ada 22 nilai dan yang dianggap baik oleh orang Sunda modern ada 18 (Isnendes, 2013 hlm 93).

Setelah mengkaji novel Tanjeur na Juritan Jaya di Buana, dari empat persyaratan tatakrama kepemimpinan Sunda, dicitrakan bahwa pemimpin Sunda memang dipersiapkan sedemikian rupa, terutama dari hal karakternya. Karakter calon pemimpin dibiasakan menjadi baik dengan pembelajaran-pembelajaran yang dianggap baik pula, sehingga di kemudian hari.

Parigeuing atau rahasia komunikasi pada abad sekarang, dalam novel telah tersedia aspek-aspeknya. Konsep komunikasi adalah ide yang disusun agar dalam proses penyampaian pada yang lain bisa tersampaikan secara efektif. Telah disebutkan bahwa Parigeuing adalah bisa memerintah; bisa menyuruh dengan bahasa yang tepat dan indah sehingga tidak membuat jengkel yang diperintahnya. Dalam novel diceritakan bagaimana terampilnya Prabu Wangisutah dalam memerintah, baik pada orang tua, ahli agama, sejawat, keluarga, dan masyarakat, bahkan musuhnya. Jika dibandingkan dengan ilmu modern dalam komunikasi, beliau sudah menguasai prinsip dalam berkomunikasi, yaitu: respek (hormat pada lawan bicara), empati (mampu menempatkan diri pada berbagai kondisi dan situasi), audible (mudah dipahami dan bahasa tubuh mendukung), clarity (jelas), dan humble (rendah hati) (docs.inasafe.org). Demikian juga dengan sarana komunikasi. Sarana komunikasi yang digunakan, bukan hanya lisan, tapi 
juga tertulis (surat), kekuatan spiritual, bahasa tubuh, dan media-media yang menjadi tanda bagi tokoh utama.

Dasa Pasanta atau sepuluh pedoman yang menentramkan hati, yang menjadi modal dalam melaksanakan parigeuing, teks telah pula memenuhinya . Sepuluh hal tersebut adalah: guna (mengerti perintah), ramah (ramah), hook (kagum), pesok (bangga), asih (rasa sayang), karunial karunya (rasa kasihan karena sayang), mukpruk (merayu), ngulas (memberi komentar dengan cara yang baik), nyecep (menentramkan), ngala angen (menarik simpati). Sifat-sifat para pemimpin kerajaan, Prabu Wangisutah dan Prabu Bunisora Suradipati, terutama merupakan karakter-karakter yang mempunyai keindahan pribadi. Potensi diri berdasarkan pada akhlak atau watak mulia merupakan manusia-manusia terpilih pada masanya. Hal tersebut tergambar dalam teks seperti pada kutipan-kutipan yang diketengahkan pada hasil penelitian.

Pangimbuhning Twah adalah tatakrama pelengkap penambah pamor (bertuah). Ada 12 pangimbuhning twah, yaitu: emet (hemat), imeut (teliti), rajeun (rajin), leukeun (tekun), pakapradana (berani), morogol-rogol (ingin maju), purusa ning sa (patriotik), widagda (bijaksana), gapitan (berani berkorban), karawaleya (dermawan), cangcingan (cekatan), dan langsitan (terampil). Semuanya tersedia dalam teks, artinya unsur dari tatakrama sebagai seorang pemimpin Sunda yang dipersiapkan sedemikian rupa, secara sadar atau tak sadar telah dikuatkan oleh penulis. Terlebih lagi penulis menggunakan refensi naskah Siksa Kanda (ng) Karesian dan naskah Wangsakerta sebagai pedoman ajaran Sunda pada sebuah kerajaan besar Sunda pada abad ke-14-16 M, bisa dianggap bahwa karakter pemimpin dan tatakrama kepemimpinan Sunda, tidak akan jauh berbeda dengan fakta sejarahnya.

Hal yang menarik adalah Opat Larangan atau empat larang dalam tatakrama kepemimpinan Sunda, sama sekali tak ditemukan teks yang mengarah ke sana. Justru empat larangan tersebut ditemukan pada tokoh-tokoh bawahan dan rakyat jelata. Artinya, karakter utama tokoh kita dicitrakan sebagai pemimpin yang hampir sempurna, baik secara fisik, mental, rohani, dan spiritualnya.

Praktek pendidikan berbasis kearifan lokal yang terdapat dalam teks berpusat pada pembentukan kakater kepemimpinan. Seperti disebutkan sebelumnya bahwa pendidikan berdasarkan pada kearifan pada setiap suku bangsa bisa universal atau unik komunal. Seperti yang terdapat pada teks, jelas ini merupakan kearifan orang Sunda yang muncul dari kebaikan, pembiasaan, harapan, dan tujuan yang ingin dicapai oleh orang Sunda secara umum.

Pendidikan yang berdasarkan pada budaya Sunda dalam novel ini, seperti disebutkan sebelumnya empat jenis, yaitu: 1) suksesi kepemimpinan dalam pemerintahan kerajaan, 2) pendidikan kepemimpinan, 3) pendidikan agama dan budi pekerti, 4) strategi mempertahankan pemerintahan kerajaan. Suksesi kepemimpinan dalam sebuah kerajaan tentunya dipengaruhi juga oleh intrik-intrik politik, ada berbagai cara suksesi dalam kepemimpinan orang Sunda baik yang positif maupun negatif. Pada teks diketengahkan suksesi kepemimpinan yang positif, baik, dan damai, yaitu penyerahan tampuk kerajaan dari wali (paman) ke keponakannya (putra mahkota yang berhak) tanpa pertumpahan darah dan intrik politik yang jahat. Ini terjadi karena adanya kepercayaan dan karakter baik pada pemimpin yang menjadi wali.

Keempat hal yang dipandang sebagai kearifan lokal orang Sunda pada abad ke-14-16 M, tentunya ditemukan atau dilakukan oleh manusia-manusianya yang baik sehingga terjadi penguatan (reinforcement) pada pembiasan yang baik itu. Seperti pendidikan kepemimpinan, pada masa modern, pendidikan formal 
kepemimpinan terbagi dua, yaitu generasi yang dipersiapkan menjadi birokrat (pemimpin wilayah) dengan pendidikan khusus (STPDN) dan generasi yang dipersiapkan menjadi ksatria militer dengan pendidikan kemiliteran. Ternyata pada novel dualisme seperti itu tidak ada. Terjadi dan terlaksana pendidikan integral komprehensif pada generasi muda yang dipersiapkan sebagai calon-calon pemimpin. Para calon tersebut dididik dengan metode pendidikan yang sama, tanpa ada perbedaan tempuh jalur birokrat atau militer.

Pendidikan dasar yang utama adalah konsep kanuragan atau yang disebut puragabaya. Calon pemimpin dibina jiwaraganya di Binayapanti Jampang dari umur 6-7 tahun hingga berumur belasan tahun. Setelah itu dilepas untuk mencari sendiri pengalaman lainnya yang berhubungan dengan kepemimpinannya. Ada yang langsung menjadi prajurit, ada yang diangkat menjadi pemimpin, tentunya dengan talentanya masing-masing, baik di kelas sosial rendah ataupun kelas sosial tinggi. Bila dibandingkan dengan pendidikan modern sekarang ini, pendidikan para calon pemimpin kerajaan tersebut telah melalui metode pembelajaran sebagai berikut: 1) pembelajaran langsung, 2) pembelajaran tidak langsung, 3) pembelajaran interaktif, 4) pembelajaran melalui pengalaman, 5) pembelajaran mandiri (docs.inasafe.org).

Pembelajaran langsung merupakan pembelajaran yang diarahkan langsung oleh pelatih atau guru. Hal ini teralami oleh tokoh utama. Ketika di Binayapanti Jampang, beliau selalu dibimbing oleh gurunya. Pembelajara tidak langsung diperolehnya ketika Prabu Wangisutah berkelana, banyak pembelajaran yang disadarinya kemudian membuahkan hasil belajar ketika dirinya menjabat sebagai raja. Pembelajaran interaktif adalah beliau mendapat ilmu dari diskusi-diskusi dengan pamandanya, Prabu Bunisora, dari para wasi dan purohita, bahkan dari musuhnya.
Pembelajaran melalui pengalaman adalah ketika beliau menyamar; bermain peran; menjadi wasi muda yang berguru di beberapa pertapaan, bahkan sampai bisa belajar membuat panah dan menembus kerajaan Majapahit. Berhadapan langsung dengan Gajah Mada, musuh besarnya dan menyaksikan penderitaan mahapatih itu, membawanya pada refleksi diri dan kehikmahan. Pembelajaran mandiri adalah ketika beliau menerima menjadi raja dan belajar pada kasepuhan ilmu-ilmu kepemerintahannya. Beliau juga memimpin projek membuat parigi di sekeliling keratonnya yang terinspirasi dari pekerjaan nenek moyangnya: Sang Batari dari Kerajaan Galunggung. Semua itu merupakan hasil dari kebaikan-kebaikan budaya yang dapat diambil contoh dari segi pendidikan oleh masyarakat modern sekarang ini.

Dari perbandingan tatakrama, terutama Dasa Pasanta dan Pangimbuhning Twah, terdapat 22 aspek karakter calon pemimpin, sedangkan dari tatakrama kepemimpinan sekarang terdapat 18 aspek calon pemimpin. Bila dibandingkan, bisa dianggap tatakrama kepemimpinan masa lalu lebih unggul dari masa sekarang. Uniknya pada dua karakter tatakrama masa lalu dan masa sekarang, tidak ada yang menyebut bahwa pemimpin harus pintar (kognisi), tetapi ke-22 aspek karakter calon pemimpin tersebut memperlihatkan kecakapan secara umum: kognisi, afeksi, dan psikomotor.

Tentu saja mengupayakan pendidikan karakter pemimpin tidak mudah, perlu disusun strategi mengajarkannya. Oleh sebab itu, untuk menguatkan karakter calon pemimpin, terutama di sekolah, bisa melalui 11 langkah atau prinsip demikian:

1) mempromosikan nilai-nilai dasar etika sebagai basis karakter;

2) mengidentifikasi karakter secara komprehensif supaya mencakup pemikiran, perasaan, dan perilaku; 
3) menggunakan pendekatan yang tajam, proaktif, dan efektif untuk membangun karakter;

4) menciptakan komunitas yang memiliki kepedulian;

5) memberi kesempatan kepada peserta didik untuk menunjukan perilaku yang baik;

6) memiliki cakupan terhadap kurikulum yang bermakna dan menantang yang menghargai semua peserta didik, membangun karakter mereka, dan membantu mereka untuk sukses;

7) mengusahakan tumbuhnya motivasi diri dari para peserta didik;

8) memfungsikan seluruh komponen lingkungan peserta didik sebagai komunitas moral yang berbagi

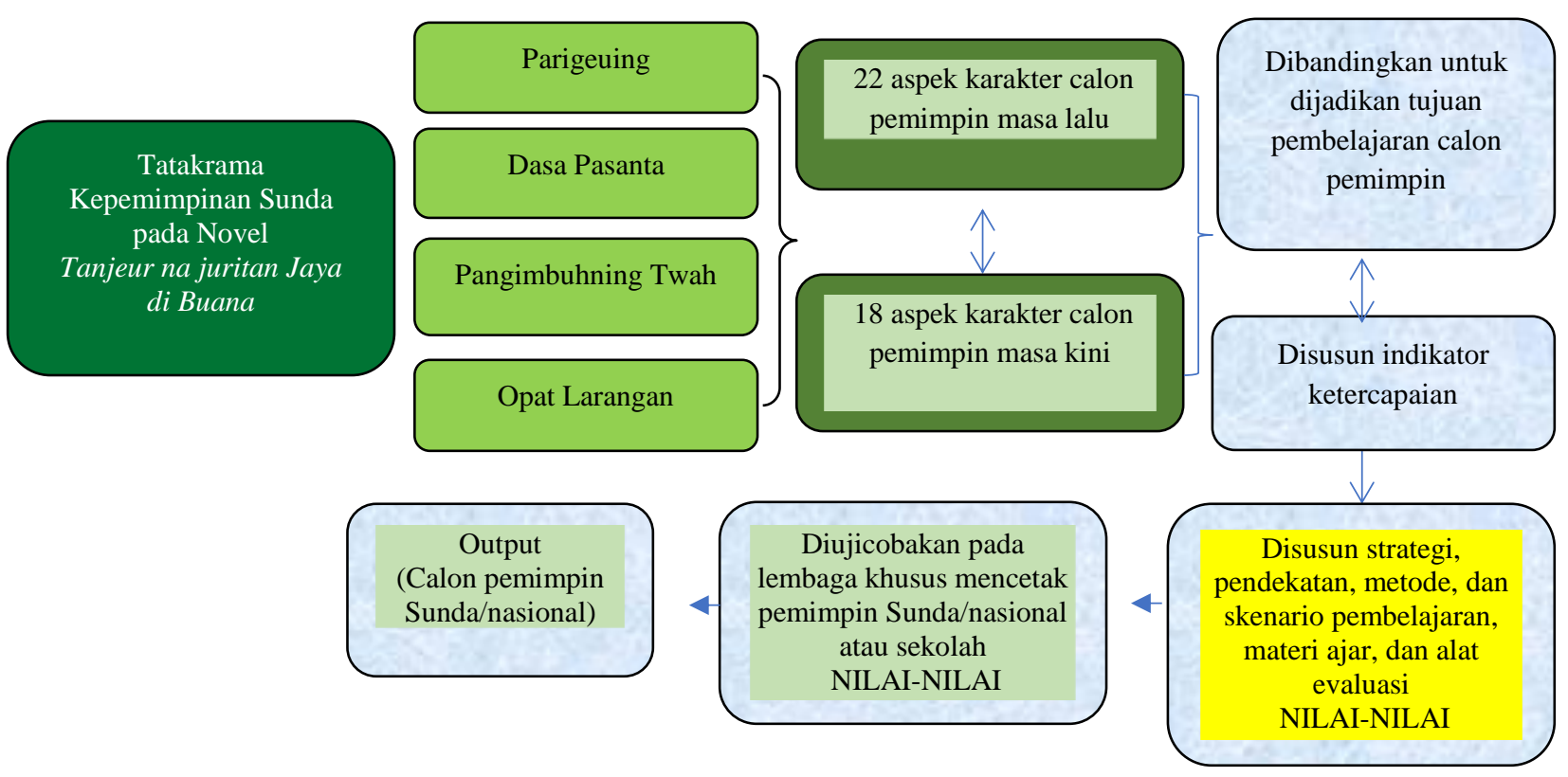

Model Pendidikan Tatakrama Pemimpin Sunda/ Nasional

\section{SIMPULAN}

Tatakrama kepemimpinan Sunda mempunyai empat aspek aturan, yaitu: parigeuing, dasa pasanta, pangimbuhning twah, dan opat larangan. Pada novel tanjeur na Juritan Jaya di Buana, terdapat ketiga aspek tatakrama kepemimpinan Sunda, adapun opat larangan tidak tersedia dalam teks. Artinya, karakter calon pemimpin dalam novel tersebut adalah karakter ideal dan lurus, dan opat larangan tanggung jawab untuk pendidikan karakter dan setia kepada nilai dasar yang sama;

9) adanya pembagian kepemimpinan moral dan dukungan luas dalam membangun inisiatif pendidikan karakter;

10) memfungsikan keluarga dan anggota masyarakat lainnya sebagai mitra dalam usaha membangun karakter;

11) mengevaluasi karakter lingkungan peserta didik, fungsi staf lingkungan didik sebagai guru-guru karakter, dan manifestasi karakter positif dalam kehidupan peserta didik (Isnendes, 2013: 94).

Model pendidikan tatakrama pemimpin Sunda/Nasional bisa disusun demikian belajaran calon pemimpin

susun indikator ketercapaian Disusun strategi, pendekatan, metode, dan skenario pembelajaran, evaluasi

NILAI-NILAI sama sekali tidak pernah ditabrak oleh tokoh utama Prabu Wangisutah.

Etnopedagogik yang terdapat pada novel Tanjeur na Juritan Jaya di Buana, berpusat pada keunikan mempersiapkan kepemimpinan Sunda yang bersipat universal sekaligus unik. Etnopedagogik yang dapat dipelajari oleh manusia modern adalah: 1) suksesi kepemimpinan dalam pemerintahan kerajaan, 2) pendidikan kepemimpinan, 3) pendidikan agama dan 
budi pekerti, 4) strategi mempertahankan pemerintahan kerajaan.

Perbandingan tatakrama kepemimpinan Sunda masa lalu dan masa kini, bisa diakumulasi dari aspek dasa pasanta dan pangimbuhning twah yang mempunyai 22 nilai karakter. Adapun tatakrama kepemimpinan masa kini bisa diambil dari rumusan karakter kemendiknas yang telah dielaborasi dengan nilai-nilai kekinian. Ternyata empat nilai tidak ada dan itu akan mempengaruhi karakter pemimpin kemudian. Selain itu model disusun sebagai panduan dalam melaksanakan tatakrama kepemimpinan Sunda atau lingkup nasional.

Saran ditujukan pada lembaga pendidikan, pemerintahan Jawa Barat dan nasional, agar dapat mempersiapkan generasi pemimpin di masa depan dengan megelaborasi tatakrama kepemimpinan Sunda dengan kepemimpinan Islam dan masa kini.

\section{UCAPAN TERIMA KASIH}

Penulis mengucapkan terima kasih kepada tim penyunting jurnal Lokabasa atas dipublikasikannya penelitian ini.

\section{CATATAN PENULIS}

Penulis menyatakan bahwa tidak ada konflik kepentingan terkait publikasi artikel ini. Penulis mengkonfirmasi bahwa data dan artikel ini bebas plagiarisme.

\section{PUSTAKA RUJUKAN}

Alwasilah dkk., (2009). Etnopedagogi: Landasan Praktek Pendidikan dan Pendidikan Guru. Bandung: Kiblat Buku Utama.

Danasasmita. S. dkk. (1987). Sewaka Darma (Kropak 408), Sanghyang
Siksakandang Karesian (Kropak 630), Amanat Galunggung (Kropak 632): Transkripsi dan Terjemahan". Bandung: Bagian Proyek Penelitian dan Pengkajian Kebudayaan Sunda (Sundanologi) Direktorat Jendral Kebudayaan Dep. Pendidikan Dan Kebudayaan.

Durahman, D. (1991). Sastra Sunda Sausap Saulas. Bandung: C.V. Geger Sunten. Isnendes, R. (2013). "Stuktur dan Fungsi Upacara Ngalaksa di Kecamatan Rancakalong Kabupaten Sumedang dalam Perspektif Pendidikan Karakter" (Disertasi). Bandung: Pendidikan Bahasa Indonesia Sekolah Pascasarjana UPI.

Isnendes, C. R. (2017). Perempuan dalam Pergulatan Sastra dan Budaya Sunda. Bandung: Yrama Widya.

Suryalaga, R. H. (1994). 'Parigeuing jeung Dasapasanta Cecekelan Pamingpin Sunda" dalam Kumpulan Makalah Lembaga Kebudayaan UNPAS karya R. Hidayat Suryalaga. Bandung: UNPAS.

http://jabarprov.go.id/index.php/news/108 22/2015/02/02/Uu-RukmanaUrang-Sunda-Kudu-Manggung http://m.inilah.com/news/detail/2021452/s aatnya-urang-sunda-jadipemimpin-nasional

https://artshangkala.wordpress.com/2010/0 1/14/pangeran-wangsakerta-sangsejarawan/

https://su.wikipedia.org/wiki/Yos\%C3\%A 9ph_Iskandar https://id.wikipedia.org/wiki/Hadiah_Sastr a_Rancage/ 